\title{
Impact of Reporting on Community Healthcare Programs on the Profitability Of oil Companies in South-South Nigeria
}

\author{
${ }^{1}$ NnachiRobert Azu., ${ }^{2}$ OnuohaljeomaP \\ ${ }^{1}$ Department of Accountancy/Business Administration/Entrepreneurial Studies. Faculty of Humanities and \\ Social Sciences Federal University, Ndufu Alike Ikwo.Ebonyi State Nigeria. \\ ${ }^{2}$ Department of Business Educations, Ebonyi State College of Education IkwoEbonyi State
}

\begin{abstract}
This study sought to ascertain whether reporting on community health care programs by the oil companies in south- south Nigeria impact on the profitability of the oil companies, find out the impact of reporting on community health care programs on community- business relations. The researcher administered questionnaires to a sample of 104 respondents, representing various community/group leaders and other stakeholders in 8 selected oil rich communities of the South-South Nigeria. Hypotheses were formulated and tested with spearman correlation statistic tool via SPSS. The result revealed that reporting on community health care impact significantly on the profitability of the oil companies; and also impact in great measure on the community- business relations. The implication of these findings is that the companies' profitability and community business relations will further be enhanced if business organizations especially the multinational oil companies intensify actions that will improve their financial commitment on community health care programs. It is therefore the view of the researcher that the oil companies should improve upon their financial commitment on health care programs. This will among others improve community-business relations
\end{abstract}

Key words: Healthcare,community-business relations, reporting, South-South Nigeria.

\section{Introduction}

The focus of community health is to give the highest level of health care for all people in the community and as such it includes that of physical, mental, social and spiritual health. Alakija[1]said that the areas covered by community health include:Community Structure (Demography) Community function (Sociology)Pattern of disease (Epidemiology)Organization and administration of different services like: environmental control, immunization and child spacing, nutrition, health education.Organization and administration of seminar that may be provided for special groups in the community, e.g.Mothers and young children, School children, Workers and Handicapped.Effective community health therefore appears central to the socio-economic development of any country considering the framework and the general impact of good health care on human life. Accordingly, business organization whose actions affects more on the health of the stakeholders has more to do in term of health care services and program especially as it affect the stakeholders not only shareholders. Oil exploration is such of those activities that imposes severe health challenges on both human and non human elements in the society. In a study by Sam [2] on the health effect of oil spill in Baraale, he revealed that Ogoni people are still feeling the harsh effect of the oil activities by Shell a decade after Shell has stopped its operation on their land. Hurst, [3] opines that business ethics addresses the responsibilities that a business organization has including health care responsibilities to each of its stakeholders' i.e. those who have a vested interest in the decisions and others who are affected by the actions of a company. But in reality especially in health care provision; most business organizations only care for their employees and management. According to Gul[4], sustainability report serves as a link to society in general and to the communities in particular where businesses are situated.

Community health is part of medicine which is concerned with the health of the whole population and the prevention of diseases from which the population suffers. The community resources are utilized principally in solving their health challenges and problems. The resources from government and private sector can also be used in addressing these challenges.

Objective 1:To find out whether reporting on community health care programs by the oil companies in southsouth

Nigeria impact on the profitability of the oil companies

Objective 2:To determine the impact of reporting on community health care programs by the oil companies in south- south Nigeria on community-business relations. 


\section{Hypothesis One}

$\mathbf{H}_{\mathbf{O}}$ : Reporting on community health care programs by the oil companies in south- south Nigeria does not impact on the profitability of the oil companies

$\mathbf{H}_{1}$ Reporting on community health care programs by the oil companies in south- south Nigeria does impact on the profitability of the oil companies

\section{Hypothesis Two}

$\mathbf{H}_{\mathbf{O}}$ Reporting on community health care programs by the oil companies in south- south Nigeria does not impact on community-business relations.

$\mathbf{H}_{\mathbf{I}}$ Reporting on community health care programs by the oil companies in south- south Nigeria does not impact on community-business relations.

\section{Literature Review}

Traditionally, health care services work to improve and maintain individual and community health. The actions of oil companies are clear reasons for several health challenges in the communities and as such should be a basis for reporting by the oil giants. In a survey conducted with 27 internationally renowned expert in Niger Delta revealed that incompetent leadership and oil corruption in the region among other factors have exacerbated the transmission of HIV in the region, the study therefore solicited that oil companies in the region should start implementing HIV prevention programs as part of their corporate social responsibility to the communities [5]. The activities of oil exploration are one that attracts expertise and foreigners to communities. The trend influences the socio-cultural behavior of the communities. The popular flexing lifestyles associated with the people of the region can be attributed to undue exposure to negative lifestyle traceable to or applicable in the oil industry. In a recent study conducted by Olujimi, Adewunmi and Odunwole[6], in some communities of South- South Nigeria shows that pollutants in form of emitted hydrocarbons caused by un-burnt crude oil and partially burnt hydrocarbons are source of pollution in area, Gases such as nitrogen oxides tetraethyl lead and carbon dust particles pose problem to human health. Grand level ozone accumulation and carbon- monoxide also cause respiratory problems. These problems in most cases manifest in cardio-vascular and neuro behavioral deficiency that may result to lung problems. It also shows that $10 \%$ of the sampled respondents had suffered from lung related health problems.

The need of stakeholder should inform the content of reporting. In recent years there have been increasing environmental challenges across the countries of the world. These challenges have been greatly attributed to increasing business activities without adequate attention to the human environment. As population grows and industrial activities also increase, there is also the tendency that the magnitude of environmentally caused morbidities has gone so high. The nature and the pattern of these adverse effects is usually a function of the features of environment where the businessopportunities. The business activities include the activities by the petroleum industries on the South-South region. It is on record that more than $20 \%$ of total gas flared in the world occurs in the South -South communities of Nigeria. This is because a large proportion of petroleum in Nigeria is found in the countries region of the South -South. The South -South communities is the largest oil reserve in African and the $10^{\text {th }}$ largest in the world. Record from the Nigeria Petroleum Ministry holds that there are about 150 oil fields and 1,481 oil wells in the South-South region. This large oil zone as a result of high concentration of oil has attracted various oil multinationals and other oil related industrial/business establishments who operate in the region. Their activities appear to affect the quality of the environment and by extension the health of the entire communities where they operate. It has been observed that oil activities especially oil exploration causes a lot of harm to the environment. These include the contamination of both surface and ground waters by benzene, xylene tolerance, ethylbenzenejenivatives. These contaminations of oil spills and other leakages also increase reforestation, economic loss and environmental degradation. The effect of these spills on the health and environment is worsened by the continuous gas flaring in the area. Studies have reviewed that gas flaring produces enormous amount of green house gases (GHG) including carbon dioxide, methane and propane. The intensity of gas flaring in Nigeria is said to be the highest among of rich regions of the world. The World Bank has also confirmed this in the recent time. The World Bank statistics on Nigerian gas flaring hold that about $35 \mathrm{~m}$ forms of carbon dioxide and $12 \mathrm{~m}$ forms of methane is said to have a more serious warming potential than carbon dioxide. Gas flaring also produces hazardous compounds that harm human health and ecosystems. Researches indicated that predominant compounds such as volatile organic compounds and others were found at highest measured $5 \mathrm{~m}$ about the sweet gas flare in Alberta Canada. Benzene naphthalene styrene, acetylene, fluorantheneanthracene, pyrene, xylene and ethylene were the richest (abundant) compounds await-able in any of the emissions examination in the sweet oil field. Apart from this, the ground 
level concentration of the products of incomplete combustion depended on the distance from the source. This is put at about $20 \%$ of maximum concentration found at a distance of $3 \mathrm{~km}$. The exposure to hazardous air pollutants emitted in the course of incomplete combustion of gas flare is known to be harmful to human health, which includes neurological cancer reproductive and developmental effects. Medical report shows that Benzene is a well known cause of leukemia (cancer of the blood) and may also cause other blood related disorder or malfunctioned. Another study in Canada shows that with $86400 \mathrm{~m}^{3} /$ day of the associated gas volume and $60 \mathrm{~m}^{3} / \mathrm{min}$ of the flare rate the concentration of benzene at $5,000 \mathrm{~m}$ was appropriately $0.25 \mathrm{~g} / \mathrm{m}^{3}$ which is more than twice higher than the annual average benzene concentration of the life time risk of 1:1,000.000 for adult leukemia $\left(0.096 \mathrm{~g} / \mathrm{m}^{3}\right)$. The level of the pollutants above with family pollutants in Alberta could only be a fraction of those in South -South region because of lower efficiency and poorer operative system existing in south -south communities. The Global Reporting Initiative [7] confirmed that there is true value to be gained from sustainability reporting based on the GRI sustainability reporting framework. But to get this value, business organizations has to choose a plan and implement a reporting style which can actually bring this value to reality. Health care program within Sustainability reporting is very essential to prosperity of companies as it provides the opportunity to demonstrate the human face of business organization. God health care facilities by oil multinational in South-South communities are primarily provided for staff of the oil companies ; whereas the people who live with the health effect of their activities are relegated to the background; which is not suppose to be so. Sustainability reporting strategy in health care will proactively find out the health need of communities and act in a suitable ways to address those challenges through strategic services and other health care programs.

The focus of a sustainability program is how business organization aligns their values and actions with the expectations and needs of stakeholder not just investors. The stakeholders here represent the employees, supplies, communities, and society as a whole. Hancook[8]said that in most cases, there is no statutory requirement or regulations that act as control or mandate business sector to be directly responsible or to voluntary take positive steps in community health sector. This is possibly why the private sector has not been fully engaged in the healthy community process. He further identified three capital models including community model and said that a careful look at the community models shows that it put human development at the centre; this is not to say that human development should be the only goal or that other capitals should be sacrifices in the interest of human development.

\section{II.I Community Health---the Role of PHC}

According to OmoruanBamidele and Philips [19] the poor health status in Nigeria has attracted global concern. The health system in the country has not worked effectively. Despite the global induction of various reform programs, ordinary Nigeria does not yet enjoy affordable and quantity health care services. Effective Primary health care can be the basis of the healthcare system by establishing fundamental policies, programs that respond to the community health needs. Primary health care is seen as well taught out services, which are in line with local needs, which is the first point of call. Health care services of this cannot be sufficient to adequately take care of other complex health needs of the Nation. Thus health care systems should work in an integrated manner through the development of mechanisms that coordinate care across the entire spectrum of services, including referral systems. Muhammed[10]said that the origin and development of health systems in Nigeria can be classified based on the historical evolution of the nation into; before colonial era Colonial and after colonial era. In the pre colonial era, the health care system was both a combination of the traditional and the modern. This was anchored towards meeting the need of the missionaries and the slave traders; the modern system was able to serve them with basic services comparable to their level of development. In the colonial period the first national development plan was called the 10 years national development plan and social welfare (1946-1956). This was a modest, realistic, practicable adequate plan compared with the time the plan came into existence. The plan proposed for the provision of more hospitals, engaging more, especially medical doctors and perhaps it is this its therapeutic and infrastructure based orientation and disposition that has persisted up till today leading to neglect of preventive services by our policy makers[10]. The third national development plan 1975-1980 focused on issues and concerns for rural development with a need to reduce disparities between regions and localities/communities. This however gave rise to the popular basic health service scheme, with the following considerations: To delegate responsibilities to non physicians in order to mop up the deficiencies of medical doctors, to locate training centres in environment similar to where trainees will serve.

Employment of based care records to increase patient's participation in healthcare. This scheme was not successful at the long-run; (sustainable at the end) due to the neglect of more important principles of PHC like community participation and inter sectoral collaboration. This reasons for the failure portrays the importance of collaborating with communities to ensure that programs intended to them are successful. In a study by Magawa[11], it is supposed to be the first level of care for individuals and families in a community. Accordingly primary health care according to his study should at least be able to provide the following: To immunization against the major communicable diseases. To prevent and con locally endemic diseases and 
epidemics Provision of maternal and child health including family planning, issues of environmental sanitation including adequate water supply and hygiene; health education on the prevailing health problems and the methods of controlling them. Also included are adequate nutrition through promotion of food supply and proper nutrition; availability of essential drugs. Across all countries of the world, outside the earlier scheme as a result of which failed based on the circumstances prescribed above. A northern attempt at implementing PHC was done in 1980 and 1985, during this period the government began the implementation of the various programs of PHC in pieces without any attempt to integrate them and without any clearly mapped out plan and objectives, this led to the fragmentation of services with both the states and federal government pursuing different objective agreeable to them and to donor agencies that may be within to partner with then in that regard. Magawa [11] maintained that active community participation is also a crucial support activity for the PHC system. This consistent view over the years must have been responsible for a deliberate attempt to adapt and nationalize the entire components of the PHC system in 1986 which culminated in the adaption of the national health policy by the military government in 1987 and was launched in 1988.

The national health policy was a focus directed for the attainment of a level of health care that will make Nigerians live and achieve socially and economically productive lives, through the emergence and institutionalization of a comprehensive primary health care system that is promotive, protective, restorative and rehabilitative. As at 1990 the federal government has extended the PHC system coverage to all the LGAs across the country. The major juices achieved so far under the PHC system include the rolling out and the entrenchment of the Bamako Initiative in 1988, the complete demarcation of the roles and responsibilities of the three tiers of government, the introduction of the referral system as well as the establishment of schools of health technologies to provide available and affordable critical manpower gaps in the sectors, the institutionalization of the concept of ward and village development committees as well as some degree of intersectional collaboration. Others are the establishment of the national primary health care development agency that will support government in monitoring PHC plan and implementation and provide continuous technical assistance to the government in PHC implantation in 1992. In his view Olakunde[12 ] opines that the way a country finances its health care system is a key determinant of the health of its citizenry.

Therefore the selection of adequate and efficient method of financing health care coupled with organization delivery structure for health services is very essential if a country is set to achieve its national health objectives of providing quality and affordable health for all. The target of the national health policy in Nigeria is to ensure comprehensive health care system; based on primary health care that is:-

Promotion, Protection, Prevention, Restoration and Rehabilitative. Accordingly, discussions below are focused on these facts in line with the literature review and in accordance with objectives. Oil exploration and business generally impose severe health risks to communities where these activities take place. The effect of oil spillage, gas flaring to human health is enormous as identified in the study by Sam [2] and later Olujimi, Adewumi and Odunwole[6]. Ron Vanden Berg in his forward to Environmental impact Assessment (EIA) process; a manual for EIA Execution in SPDC wrote, "we must continue to work with external stakeholders to manage the impact of our operations on the environment in which we operate. If we don't get this process right, SPDC and its host communities can have no sustainable future. Our EIA process up till now has been very largely about the natural environment much less about the human environment."

There has been little or no consideration on human effects of oil activities in the South-South communities. This accounts for the reason why over $20 \%$ of global gas flaring occurs in South-South communities. Hancock [8] said the means of increasing economic capital must not threaten either our human/social and environmental capital upon which we depend for our health and well being. When there is abuse of the environment in form of contamination of water or air, the implication is that the health conditions of the people will suffer. Naagbunton[13] reported that shell could be forced to clean up the environmental devastation it has caused and to pay more than $\$ 400 \mathrm{~m}$ as compensation for environmental and social injustice. It is therefore pertinent to note that environmental, social and economic injustice especially occasioned by oil activities affects health condition. One striking point is that health care programs has never been considered as a variable upon which sustainability reporting in South- South communities can focus on. An evaluation of multinational oil companies' activities especially in the developed world indicates that there is little or no health issues. Their system does not allow people to be exposed the way it happens in the developing world like Nigeria. This could be the reason why it is not an issue for these countries. But for Africa and more especially Nigeria, it is necessary because it is a local content need. This is in line with the opinion by Sam [2], Udoh, Stama and Mantel [5] who said that the action of the oil companies are clear reasons for several health challenges in the communities and as such should be a basis for reporting. Good business ethics addresses the responsibilities that a business organization has including health care responsibilities. Non adherence to good business ethics by the oil companies has been the reason for high health risk in these communities. Sustainability report serves as a link between the society and business organizations and to communities in particular where businesses are situated. Since the communities have unanimously agreed that the health risk 
associated with oil activities are massive; it therefore become imperative that inclusion of health care programe as sustainability reporting variable will impact significantly in promoting community business relationship. Yes there is a true value to be gained by the oil companies, but to get this value, the oil companies has to choose a plan and implement a reporting style which can actually bring this values to reality. Reporting on health care programs in sustainability report of the oil companies in Nigeria is very essential to the well being of the companies as it provides opportunity to demonstrate human face of business organization. This is because the focuses of sustainability reporting are on how business organization aligns their values and actions with the expectations and the need of stakeholder and not just investors.

\section{Methodology}

The study adopted a cross-sectional survey research design This type of research design utilizes different groups of people who differ in terms of interest but share other characteristics such as socioeconomic status, educational background and ethnicity; it is often used when considering the prevalence of something in a given population. Cross sectional survey design was adopted because this study therefore utilizes different groups of people (community leaders from various communities) from distinct and separate communities across different ethnic groups and states, but share a similar socioeconomic status. The study was carried out in 8 selected oil rich communities in South-South Nigeria; The researcher adopted a sample size technique called creative research system sample technique.

Formula $=$

Sample Size $=\mathrm{n} /[1+(\mathrm{n} /$ population $)]$

Where $\mathrm{n}=\mathrm{Z} * \mathrm{Z}[\mathrm{P}(1-\mathrm{P}) /(\mathrm{D} * \mathrm{D})]$

Where $\mathrm{P}=$ True proportion of factor in a given population or the expected frequency value.

Where $\mathrm{D}=$ Maximum difference between the sample mean and the population mean or the expected frequency value minus (-) worst acceptable value.

Where $\mathrm{Z}=$ Area under normal curve corresponding to the desired confidence.

Confidence level $=95 \%=1.960$

Expected frequency of the factor under study $=50 \%$

Population of study $=341$

Confidence interval $=8 \%$

The provision for the confidence interval at $8 \%$ is based on the complexity of the population components. A confidence interval is used to express the uncertainty in a quantity being estimated. This uncertainty exists because inferences are based on a random sample of finite size from a population or process of interest.

Worst acceptable frequency $=50 \%-8 \%=42 \%$

Formula

$\mathrm{n} /[1+(\mathrm{n} /$ population $)]$.

Where $\mathrm{n}=\mathrm{Z} * \mathrm{Z}[\mathrm{P}(1-\mathrm{P}) /(\mathrm{D} * \mathrm{D})]$

First we will calculate the value for ' $n$ '

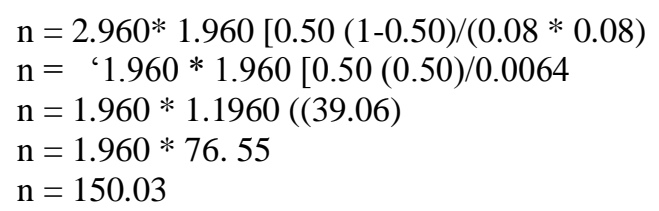

Then we will calculate the sample size $=\mathrm{S}$

$\mathrm{S}=\mathrm{n} /[1+(\mathrm{n} /$ Population $)$

$\mathrm{S}=150.03 /[1+(150.03 / 341]$

$\mathrm{S}=150.03 /[1+0.439970]$ 


$$
\begin{aligned}
& S=150.03 / 1.439970 \\
& S=104
\end{aligned}
$$

This technique applies in determining sample size in a situation where the study is focusing on the observation or a behavior of a representative subset. The target of the study is the entire South-South Nigeria; but study will however make inferences based on the opinions of community leaders in critical issues under considerations by this study from selected communities to represent the entire position of the people of SouthSouth Nigeria. The researcher developed and administered structured questionnaire to the staff in public relation departments/units of each of the 4 selected oil companies and to community leaders of 8 of the selected oil rich communities (the representatives of town/community unions and groups and opinion leaders of each of the 8 selected communities). Their responses were used for data analyses. Data were collected from these groups of respondents using a survey instrument that incorporates both open and close ended questions. The researcher used Spearman correlation as a statistical tool and technique of data analysis of this study. This was achieved via the use Statistical Programming for the Social Sciences (SPSS) package 17.0 version.In order to convert the ordinal scale to interval scale a weighting was given to each of the responses in the scale. (Likert scale)

Research Objective 1:To find out whether reporting on community health care programs by the oil companies in south- south Nigeria impact on the profitability of the oil companies

Research Objective 2:To determine the impact of reporting on community health care programs on community-business relations.

In order to generate valid response to the third research question, analyses were carried out by using the responses from Item 36 and 37 of the questionnaire. The questions bother on whether reporting on community health care programs by the oil companies in South- South communities' impact on the profitability of the oil companies Table 1 represents the cross tabulation of the two variables used in the analysis of the hypothesis.

RCHCP is a code for questionnaire item no.36; and it represents responses on whether the oil companies should report on community health care in their sustainability reports.

RCHCPCCBR is a code for questionnaire item no.37; and itrepresent responses on reporting on community health care program by the oil companies operating in the community and its impact on the profitability of the oil companies in South-South Nigeria.

Accordingly,69(66\%) strongly agreed that the oil companies should report on community health care programs, 27 or (26\%) agreed, only 1 respondent was undecided. On the contrary 4 respondents representing $4 \%$ disagreed while 3 respondent representing 3\% strongly disagreed. On the second variables which deals with the impact of reporting on community health care programs on the profitability of the oil companies in SouthSouth Nigeria , 69 respondents representing 66\% strongly agreed, 25 or $24 \%$ agreed while 3 were undecided on the issue, however, on the contrary only 6 respondents representing or $5 \%$ disagreed while only 1 respondents strongly disagreed.

\section{Results}

\begin{tabular}{|c|c|c|c|c|c|c|c|}
\hline COUNT & & & & & & & \\
\hline & & \multicolumn{5}{|c|}{ RCHCPCBR } & \multirow[b]{2}{*}{ TOTAL } \\
\hline & & SD & D & $\mathrm{U}$ & A & SA & \\
\hline \multirow[t]{5}{*}{$\mathrm{RCHCP}$} & SD & 0 & 3 & 0 & 0 & 0 & 3 \\
\hline & D & 1 & 3 & 0 & 0 & 0 & 4 \\
\hline & U & 0 & 0 & 0 & 1 & 0 & 1 \\
\hline & A & 0 & 0 & 2 & 15 & 10 & 27 \\
\hline & SA & 0 & 0 & 1 & 9 & 59 & 69 \\
\hline TOTAL & & 1 & 6 & 3 & 25 & 69 & 104 \\
\hline
\end{tabular}

Table 1: Rchcp * Rchcpcbr Cross Tabulation

Source: SPSS output 


\begin{tabular}{|c|c|c|c|c|}
\hline & & & RCHCP & RCHCPCBR \\
\hline \multirow[t]{2}{*}{ Spearman's rho } & RCHCP & $\begin{array}{l}\text { Correlation Coefficient } \\
\text { Sig. (2-tailed) } \\
\text { N }\end{array}$ & $\begin{array}{r}1.000 \\
. \\
104\end{array}$ & $\begin{array}{r}.636^{* 27} \\
.000 \\
104\end{array}$ \\
\hline & $\overline{\mathrm{RCHCPCBR}}$ & $\begin{array}{l}\text { Correlation Coefficient } \\
\text { Sig. (2-tailed) } \\
\text { N }\end{array}$ & $\begin{array}{r}.636^{* *} \\
.000 \\
104\end{array}$ & $\begin{array}{r}1.000 \\
104\end{array}$ \\
\hline
\end{tabular}
Source: SPSS output

Table 3: Case Processing Summary

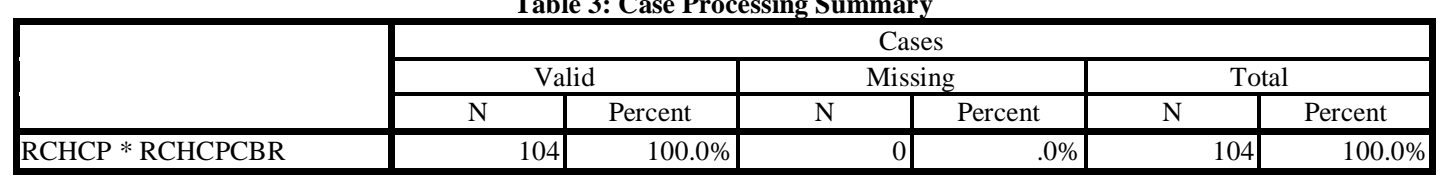

Source: SPSS output

\begin{tabular}{|c|c|c|c|c|c|}
\hline $\begin{array}{l}\text { Interval by Interval } \\
\text { Ordinal by Ordinal } \\
\mathrm{N} \text { of Valid Cases }\end{array}$ & $\begin{array}{l}\text { Pearson's R } \\
\text { Spearman Correlation }\end{array}$ & $\begin{array}{l}.822 \\
.636 \\
104\end{array}$ & $\begin{array}{l}.049 \\
.081\end{array}$ & $\begin{array}{r}14.596 \\
8.318\end{array}$ & $\begin{array}{l}.000^{\circ} \\
.000^{\circ}\end{array}$ \\
\hline
\end{tabular}

a. Not assuming the null hypothesis.

b. Using the asymptotic standard error assuming the null hypothesis.

c. Based on normal approximation.

Source: SPSS output

Based on the SPSS result on tables 2 and 4, we can infer that the Spearman correlation coefficient value of .636 implies a positive correlation between the two variables and the P-Value for this test (.000) means that the test for the level of significant is less than the pre-set value of 0.01 . Therefore we can say that we have a strong evidence to accept the Alternative hypothesis and reject the Null Hypothesis (Accept $\mathrm{H}_{\mathrm{I}}$ and reject $\mathrm{H}_{0}$ )

\section{Decision}

A Spearman's correlation was run to determine the relationship between reporting on community health care programs and impact on the profitability of the oil companies. There was a strong, positive correlation between the two variables $\left(\mathrm{r}_{\mathrm{s}}=.636, \mathrm{n}=104, \mathrm{p}<0.01\right)$. Therefore, reporting on community health care programs impact significantly on the profitability of the oil companies in South-South Nigeria.

\section{Conclusion}

Community Healthcare Programs is a vital ingredient of sustainability reporting in the business of the oil companies in South-South Nigeria

According the result of the descriptive statistics of RCHCPBP and HHR show that:

1. The communities are in serious need for effective and efficient grass root healthcare programs.

2. The communities are aware of the severe health implication of oil exploration and other activities in their respective communities. That reporting on community health care programs in South- South Nigeria results in the provision of adequate and affordable health care services. This is achieved by regular identification of peculiar health challenges caused by the activities of the oil companies; creating necessary awareness as regards to their effect among the people; and also using these health challenges as benchmarks in managing and controlling the effect of those health challenges. This however impacts positively on the profitability of the oil companies and by extension promote community- business relations. As a result of weak regulatory framework, the oil multinational companies in Nigeria do not have well structured indigenous version of their sustainability reports that addresses local environmental and social challenges. (Local content environmental and social variables). Accordingly their reporting strategies are still being criticized for incompleteness, inconsistency and also lacking necessary input from stakeholders/community leaders who are directly affected by their activities. Also none availability of even a single sustainability reporting framework in Nigeria, accounts for lack of monitoring in this regard by appropriate authorities and other relevant stakeholders like the community so as to make the oil companies comply with the world best practices. 


\section{Recommendations}

That the oil companies operating in the South-South communities should

1 ) Commence reporting on community health-care program as a distinct variable in their sustainability report which is not currently happening. This has become necessary because of the huge health risks constituted by oil exploration activities in these communities. 2) Develop a more transparent approach in dealing with health challenges occasioned by oil activities in these communities; and employ strategic evaluation and reporting mechanism that will encourage stakeholders' involvement. This will among other thingsimpact significantly on community-business

\section{References}

[1] Alakija, W. (2000). Essentials of Community Health Care and Health Management.Medisucess Publication Benin City P 495

[2] Sam, O. (2002). Shell's Oil Spill in Baraale, Ogoniland of Nigeria's Rivers State October, 2001 January 2002, Environmental Right Action (ERA) Field Report number\#89, Tel / Fax + 23452600 / 65, E- mail eraction@inforweb-abs.net, Benin City Nigerian. Retrieved on 16/08/2012.

[3] Hurst, S. (2004). US and Norwegian Healthcare System (www.w/u.edu/documents/shepherd/academic/cap-07-hurst.pdf).Retrieved on $15 / 02 / 2013$.

[4] Gul, M.F. (2007). Corporate Social Responsibility within Healthcare Business http/www.drfameg.com/ Retrieved on 31/01/2013.

[5] Udo, I., Stammen, R.M and Mantell J.E (2008) Corruption and Oil Exploration; Expert Agreement about the Prevention of HIV/AIDS in the Niger Delta of Nigeria .Health Education Research Oxford Journal 2008 August Vol. 23 (4): pp 670-681

[6] Olujimi, J.A, Adewumi, E.A. and Odunwole, S. (2011). Environmental Implications of Oil Exploration and Exploitation in the Coastal Region of Ondo State.Journal of Coastal of Region of Ondo State.Journal of Geography and Regional Planning vol. 4 (3) pp110-121.

[7] Global Reporting Initiative. (2010).Sustainability Reporting for SME'S. A Seminar Paper by Global Reporting Initiative Focal Rout Australia presented 8:45am __ 11:am in Tuesday 24th November 2010 at Net Balance, Level 4, 460 Bourke Street, Melbourne. . Retrieved on 19/05/2011.

[8] Hancock, T (2013) People, Partnership and Human Progress: Building Community Capital, Health Promotion International Journal Vol.16 (3) pp 275-280

[9] Omoruan, A. I. Bamidele, A.P and Philips, O. F (2009). Social Health Insurance and Sustainable healthcare reform in Nigeria. Department of General studies LadokeAkintola University of Technology P.M.B 4000 Ogbomosho, Nigeria. Ethno med. Vol. 3 (2) Pp 105-110

[10] Muhammed, K.A. (2009). Assessment of Barriers to Utilization of Primary Health Care Service in Batsari Local Government Area of Kastina State.Department of Community Medicine AhmaduBelloo University Zaria.Retrieved on 20/4/2013.

[11] Magawa, R. (2012). Primary Health Care Implementation: A Brief Review. A Discussion Paper on Public Health Care Implementation on 16 August 2012.

[12] Olakunde, B o (2012). Public Health Care Financing in Nigeria. Which Way Forward? Department of Programme Coordination. National Agency for the Control of Aids Abuja, Nigeria. Annals of Nigerian medicine journal vol. 6 (1) Pp 4-10

[13] Naagbunton, P. (2011). Justice in Nigeria Now for Human Right Environmental Protection and Community Livelihood 